\author{
О.Б. Дашинамжилов ${ }^{*}$ \\ В.В. Лыгденова ${ }^{* *}$ \\ Демографическое развитие \\ автономных округов России в 1960-е - \\ 1980-е гг.: проблемы источников
}

DOI: 10.31518/2618-9100-2019-4-16
УДК 314.015 + 314.02 (571) «196/198»

Выходные данные для цитирования: Дашинамжсилов О.Б., Лыгденова В.В. Демографическое развитие автономных округов России в 1960-е - 1980-е гг.: проблемы источников // Исторический курьер. 2019. № 4 (6). Статья 16. URL: http://istkurier.ru/data/2019/ISTKURIER-2019-416.pdf
O.B. Dashinamzhilov

V.V. Lygdenova

\section{Demographic problems of autonomous regions of Russia in 1960-1980s: problems of resources}

\author{
DOI: $10.31518 / 2618-9100-2019-4-16$
}

How to cite:

Dashinamzhilov O.B., Lygdenova V.V. Demographic problems of autonomous regions of Russia in 19601980s: problems of resources // Historical Courier, 2019, \#4(6). Article 16. [Available online:] http://istkurier.ru/data/2019/ISTKURIER-2019-416.pdf

Abstract. In the paper by the example of two autonomous districts statistical resources that are the basis for demographic development of these two groups of administrative units of Russia are researched. Materials of All-Union Census which major part is in Russian State Archive of Economics and partially in the State Archive of the Russian Federation are the main resources. It is noted that for a detailed research of territorial processes of population it is necessary to refer to the fonds of regional state archives. You might rarely find Census materials in the libraries of scientific organizations. The most demanded information was published in a short form in a limited circulation in the collections for official use. Some part of All Union Census was published openly. Central role in the official editions was given to state republics, information on regions, districts and autonomous republics in a concise form. Collection of information about births, deaths, marriages and divorces was held by current population statistics. It is found out that there was no any elaboration of demographic events in autonomous districts according to a full program. Additionally, there is no information about natural movement during a row of years in regional archives. Direct addressing to materials of the regional archives is one of the ways to complete the existing gaps, however statistic management of the regions did not fill traditional tables and kept records of demographic events in a free form. Materials of current population statistics of population and also data of Census could be published in closed editions. So, the paper represents that there is a solid statistical basis of population number, demographic and social composition of population related to autonomous regions. However it is possible to give only indirect assessment of reproduction processes in 1959-1989-s.

Keywords: historical demography; autonomous region; statistical resource; All Union Census; current population statistics; archive.

The article has been received by the editor on 22.07.2019.

Full text of the article in Russian and references in English are available below.

\footnotetext{
* Дашинамжилов Одон Борисович, канд. ист. наук, научный сотрудник, Институт истории Сибирского отделения Российской академии наук (Новосибирск, Россия), e-mail: Odon@bk.ru

Dashinamzhilov Odon Borisovich, Candidate of Historical Sciences, Research Officer, Institute of History of the Siberian Branch of the Russian Academy of Science (Novosibirsk, Russia), e-mail: Odon@bk.ru

** Лыгденова Виктория Васильевна, канд. филос. наук, научный сотрудник, Институт археологии и этнографии Сибирского отделения Российской академии наук (Новосибирск, Россия), e-mail: victoria.lygdenova@gmail.com

Lygdenova Victoria Vasilevna, Candidate of Philosophical Sciences, Research Officer, Institute of Archaeology and Ethnography of the Siberian Branch of the Russian Academy of Science (Novosibirsk, Russia), e-mail: victoria.lygdenova@gmail.com
} 
Аннотация. В статье на примере двух автономных округов исследуются статистические источники, на основе которых можно изучать демографическое развитие данной группы административных образований России. Главными источниками стали материалы Всесоюзных переписей, которые в основной массе находятся в распоряжении Российского государственного архива экономики и, частично, Государственного архива Российской Федерации.

Отмечено, что для детального изучения территориальных процессов народонаселения необходимо обращение к фондам региональных государственных архивов. Изредка переписные материалы можно обнаружить в библиотеках научных организаций. Самые востребованные сведения издавались в кратком виде ограниченными тиражами в сборниках для служебного пользования. Некоторая часть Всесоюзных переписей публиковались открыто. Центральное место в официальных изданиях отводилось союзным республикам, информация по областям, краям и автономным республикам давалась в сжатой форме.

Сбор сведений о рождениях, смертях, браках и разводах осуществлялся текущим учетом населения. Установлено, что разработка демографических событий по автономным округам по полной программе не производилась. К тому же часто в областных архивах нет информации о естественном движении за ряд лет. Одним из способов восполнения существующих пробелов является обращение к материалам непосредственно окружных архивов, однако статистические управления округов не заполняли традиционных таблиц и вели учет демографических событий в произвольной форме. Материалы текущего учета населения, также как и данные переписей, могли публиковаться в закрытых изданиях. Итак, в статье показано, что в отношении автономных округов существует солидная статистическая база, касающаяся численности, демографического и социального состава населения. Но на ее основе можно дать лишь косвенную оценку воспроизводственным процессам в 1959-1989 гг.

Ключевые слова: историческая демография; автономный округ; статистический источник; Всесоюзная перепись; текущий учет населения; архив.

$$
* * *
$$

На сегодняшний день, историческая демография стала важнейшим элементом исторической науки. Публикуются многочисленные статьи и монографии, в которых анализируются тенденции воспроизводства и миграции населения России и ее регионов. Вместе с тем, при изучении динамики народонаселения исследователи часто наталкиваются на проблему статистических источников. В нашей работе мы дадим оценку тем из них, что необходимы для изучения демографического развития особой группы российских административных образований - автономных (национальных) округов ${ }^{1}$.

Анализу статистических источников посвящено не так много работ. В трудах историков рассматривались проблемы организации и проведения переписей в СССР, полнота и репрезентативность представленной в них информации ${ }^{2}$. Исследовались принципы сбора, программы и точность текущего учета населения ${ }^{3}$. Важной вехой в изучении этой проблемы стал выход сборника научных трудов «Демографическая история России и регионов. Вып. 1. Проблемы источников» ${ }^{4}$. Между тем, ученые, сконцентрировав внимание на исследовании демографии экономических районов и крупных регионов - краев, областей и республик,

\footnotetext{
${ }^{1}$ Национальные округа - это вид административных образований, существовавший в СССР до 1977 г. в составе краев или областей, после чего они переименованы в автономные округа. В статье для удобства использованы оба термина.

2 Жиромская В.Б. Полвека под грифом «секретно»: всесоюзная перепись населения 1937 года. М.: Наука, $1996 . ;$ Исупов B.A. Статистические источники по демографической истории России периода Великой Отечественной войны. Сыктывкар, 2011.

${ }^{3}$ Демографическая истории Западной Сибири (конец XIX-XX в.). Новосибирск: ИИ, 2017.

4 Демографическая история России и регионов. Сб. научн. тр. Выпуск I: проблемы источников. Новосибирск: Изд-во «Апельсин», 2016.
} 
описанию источниковой базы небольших административных единиц уделяли меньше внимания. Именно поэтому статистические источники демографического развития автономных округов по-прежнему остаются малоизученными. В статье на примере Усть-Ордынского и Агинского бурятских автономных округов мы попытаемся восполнить этот пробел.

Всесоюзные переписи являются главными источниками данных о населении. Они являлись сложными организационными мероприятиями, благодаря которым собирались социальные, экономические и демографические сведения о жителях страны. В рассматриваемых временных рамках они проводились в среднем раз в десять лет - в 1959, 1970, 1979 и 1989 гг. Переписи послевоенного периода считаются достаточно точными, так как явных причин фальсифицировать информацию, как, например, в 1939 г. не было. В 1959 г. контрольными проверками по всей стране было выявлено только 789,0 тыс. непереписанных лиц, или 0,37\% от всего населения, в 1970 г. - 0,25\%, а в 1979 г. - 0,12\%.

Программы разработки материалов переписей несколько различались между собой. Так, например, опросный лист в 1959 г. включал в себя 15 вопросов, 1970 г. - 18, но по 11 из них ответы собирались от всего населения, остальные семь задавались выборочно 25,0 \% жителей страны. В 1979 г. он включал в себя 16 вопросов, в том числе 11 обязательных и пять выборочных. В 1989 г. - опросный лист состоял уже из 25 вопросов, на 13 из которых ответы собирались по всему населению, пять - выборочно. Вопросы с 19 по 25 касались жилищного положения и заполнялись на члена семьи, записанного первым 5 .

Для лучшего понимания изменений по каждой демографической, национальной, социально-экономической и иной группе материалы разрабатывались отдельно по городским поселениям и сельской местности, а также по мужчинам и женщинам. Причем по союзным республикам итоги переписей были самыми подробными. Так, в 1970 г. по ним было разработано 445 таблиц, по областям, краям и автономным республикам - 431-433 таблицы. По национальным округам собиралось меньше всего материалов - 331 таблица, но больше, чем, например, по крупным городам (107-143)

Для демографического исследования важными были таблицы, что заполнялись на основе записей места жительства в переписных листах. Именно этот материал стал ключевым для анализа тенденций численности населения округов, городских поселений и сельской местности, мужчин и женщин. Систематизация городских и сельских поселений по числу жителей дает возможность оценить специфику их категориального распределения. При детальном научном анализе можно привлечь информацию о каждом населенном пункте.

Для изучения демографии регионов важны таблицы, в которых указаны возрастнополовой, национальный и образовательный состав населения, его распределение по источникам средств существования и общественным группам. Например, пол и возраст в совокупности с информацией текущего учета позволяют проанализировать интенсивность воспроизводственных процессов. Половозрастные характеристики разрабатывались в комбинации с образовательной, национальной, профессиональной и другими структурами населения. Вплоть до 1970 г. вопрос о возрасте формулировался как число исполнившихся лет. В 1970 г., 1979 и 1989 гг. он стал задаваться в двух вариантах - наряду с числом исполнившихся лет записывался год рождения.

В таблицах, в которых представлялась половозрастная характеристика, распределение населения производилось по одногодичным и пятилетним возрастным группам, с выделением мужчин и женщин. Такие данные заполнялись по союзным и автономным республикам, областям (краям), национальным округам и даже районам, городам и селам с определенной численностью населения (1970 г. - 3000 чел. и выше, в 1979 г. - 5000 тыс. и более). С их помощью можно оценить темпы старения населения, соотношение между мужчинами и женщинами, рассчитать средний возраст административной единицы или поселения.

\footnotetext{
5 Дашинамжилов О.Б. Городское население Западной Сибири в 1960-1980-е годы: Историко-демографическое исследование. Новосибирск: Наука, Изд-во СО РАН, 2018. С. 30.

${ }^{6}$ Всесоюзная перепись населения 1970 года. Сб. ст. М.: Статистика, 1976. С. 99.
} 
Всесоюзные переписи являются источниками сведений о национальном и лингвистическом составе жителей страны. Число разрабатываемых народов в каждой переписи было разным, но размах вариаций был небольшим. В 1959 г. данные собирались по 128 национальностям, в 1970 г. - по 122, 1979 г. - 123, в 1989 г. - снова 128. Состав национальностей был расширен позднее, во Всероссийских переписях 2002 и 2010 гг. При ответах на вопрос о национальной принадлежности люди в ответ часто называли не общеизвестные, а местные обозначения этнографических групп, которые уже вошли в состав другого народа. Для таких случаев разрабатывался специальный словарь народов и языков, в которых указывалось, куда отнести местные названия или диалекты. Для оценки факторов воспроизводства очень важны сведения о распределении этносов по общественным группам, источникам средств существования и образованию.

По самым многочисленным национальностям республик, областей и национальных округов, республиканских и областных центров, а также крупных городов (100,0 тыс. и более) получали подробные данные, включающие кроме численности сведения о распределении по родному языку, возрасту, уровню образования, численности состоящих или не состоящих в браке. Краткая информация разрабатывалась применительно к районам, отдельным городским поселениям и крупным селам, для которых указывались только численность самых больших национальностей и их родной язык.

Для оценки культурного уровня можно использовать данные об образовании. В систематизированных таблицах они публиковались в сочетании с возрастом, общественными группами, занятыми, отдельными национальностями. Впервые вопрос об уровне образования (высшего и среднего) был включен в программу переписи 1939 г., а до того, в 1920 и 1926 гг. собиралась информация о грамотности. В 1970 г. и позднее этот вопрос в программы уже не включался ${ }^{7}$.

В переписях 1939 и 1959 гг. образовательный уровень рассчитывался относительно всего населения, в 1970 и 1979 гг. применительно к лицам в возрасте 10 лет и старше. Материалы об образовании необходимы для объяснения специфики воспроизводственных процессов и, прежде всего, рождаемости, с которой образовательные характеристики находились в обратной зависимости. Определенную корреляцию они имели и со смертностью населения.

Большое политическое значение в Советском Союзе придавалось изучению социальноклассовой структуры общества. Впервые вопрос об общественной группе был включен в программу переписи 1939 г., а до этого собирались сведения по положению в занятии. Эти материалы необходимы, например, для анализа рождаемости, так как социологические исследования выявили зависимость репродуктивных установок женщин от их общественной группы. Среди итогов Всесоюзных переписей важное место занимают выборочные исследования в отношении четверти населения, которые стали проводится, начиная с 1970 г. С их помощью можно изучать занятость, распределение населения по отраслям народного хозяйства, миграции, а с 1979 г. - рождаемость. Наибольший интерес представляет информация об итоговом числе рожденных женщинами детей.

Итогами переписи в первую очередь обеспечивались органы государственного управления. В 1970 г. на основе подробных систематизированных таблиц составлялись более компактные публикационные по каждому административному образованию ${ }^{8}$. Если в систематизированных таблицах информация представлялась очень подробно, то в публикационных часто применялись обобщенные или даже относительные (на 1000 чел.) показатели. В них использовались сопоставления с ранними переписями, укрупненные категории населения и возрастные группы. В конечном итоге, каждое республиканское, областное и окружное статистическое управление получило все результаты по подотчетной

\footnotetext{
${ }^{7}$ В переписи 1959 г. вопрос о грамотности звучал так: «Для лиц 9 лет и старше, не имеющих начального образования, указать: читает и пишет или только читает на каком-либо языке, или вовсе неграмотен».

${ }^{8}$ Судя по нашим данным, позднее деление таблиц на систематизированные и публикационные было отменено. Для представления данных переписей 1979, 1989 гг. использовались только систематизированные.
} 
территории. Часть статистических данных во многих регионах к настоящему моменту передана в государственные архивы.

Практически все таблицы Всесоюзных переписей 1959-1989 гг., в том числе с информацией о национальных округах, находятся в фондах Российского государственного архива экономики (РГАЭ). В нем сосредоточены самые полные данные о численности, возрастном, национальном и социальном составе населения (Фонд 1562). Часть таблиц была передана в распоряжение Государственного архива Российской Федерации (ГАРФ), но по количеству материалов (Фонд А. - 374) он значительно уступает РГАЭ. Особенно плохо там представлена Всесоюзная перепись 1979 г., а 1989 г. вообще отсутствует. Важная информация, правда, без предоставления выходных данных была опубликована на сайте Демоскопа (demoscope.ru). При этом, по нашим сведениям, в центральных архивах почти не было статистики небольших городов и административных единиц (районов).

Для детального изучения процессов народонаселения важно обращение к фондам региональных государственных архивов. Опыт показывает, что областные и республиканские архивы сильно отличаются по полноте находящихся в их распоряжении переписных таблиц. Облстаты лишь в редких случаях отдают на хранение все имеющиеся в их распоряжении материалы. Если рассматривать Иркутский и Читинский государственные архивы, то в первом из них переписи за указанный период вообще отсутствуют 9 . В Читинском архиве нам удалось найти небольшую часть данных Всесоюзной переписи 1959 г. Скорее всего, сведения переписей до сих пор находятся в распоряжении ведомственных архивов облстатов, доступ к которым ограничен.

Только в региональных архивах можно найти, например, информацию о возрастном и национальном составе малых или средних городов, поселков городского типа и районов. К примеру, в Читинском архиве есть информация за 1959 г. о распределении Агинского, Дульдургинского, Могойтуйского районов Агинского автономного округа по крупным (не более 10) национальностям (Ф.Р-1645). Сохранились данные об уровне образования разных этносов с разделением по возрасту и полу, материалы об источниках средств существования, распределении населения округа по отраслям народного хозяйства и т.д. Непосредственно в окружных архивах информации об итогах Всесоюзных переписей сохранилось мало, главным образом, она касалась организационных вопросов.

Очень редко, но некоторые переписные материалы можно обнаружить в библиотеках научных организаций, которые получали их для выполнения научных работ или, например, в Российской государственной библиотеке (РГБ), библиотеке ИНИОН РАН. Нами, например, таким способом были обнаружены публикационные таблицы «Распределение населения по полу, возрасту, национальности, языку, образованию, состоянию в браке и источнику средств существования» Всесоюзной переписи 1970 г. в том числе с данными об округах. Эти публикационные таблицы, видимо, издавались крупными тиражами, так как нередко встречались в других региональных архивах Сибири. Интересно, что в фондах Читинской областной библиотеки хранится несколько систематизированных таблиц Всесоюзной переписи 1989 г., в том числе по Агинскому автономному округу, его районам и некоторым населенным пунктам. Это пока единственной в нашей практике случай передачи систематизированных таблиц областной библиотеке.

Самые востребованные материалы переписей издавались в кратком виде ограниченными тиражами в сборниках для служебного пользования (ДСП). Информация в них представлялась в произвольной форме, но часто для сравнения с данными предыдущих переписей. Материалы за 1959 и 1989 г. публиковались несколько более подробно, а за 1989 г. уже открыто, без грифа «Для служебного пользования». Существенным недостатком таких статистических сборников являлась краткость и недостаточная сравнимость сведений. Это в первую очередь относится к тем из них, что были изданы по переписям 1970 и 1979 гг.

\footnotetext{
${ }^{9}$ На момент нашей работы в этих государственных архивах. Данные переписей могут передать позже.
} 
Так, например, в одном из найденных нами сборников возрастной состав населения регионов и автономных округов представлялся по укрупненным и часто нестандартным (0-2, $3-6,7-9,10-15,60$ лет и старше) возрастным группам ${ }^{10}$. Это снижало научную ценность материала и не давало в полной мере использовать его для расчетов важных демографических показателей. Самая общая информация касалась этнического состава населения. Круг разрабатываемых этносов был узким, социальные и демографические характеристики национальностей давались сжато и по небольшому количеству параметров ${ }^{11}$. Некоторые сборники можно найти в библиотеках научных организаций, в РГБ и Государственной публичной научно-технической библиотеке СО РАН (ГПНТБ СО РАН).

Аналогичные сборники часто издавались областными управлениями статистики. В них информация была, конечно, гораздо подробней, так как публиковалась по конкретному региону. Они содержали материалы переписей не только по областям и входящим в его состав автономным округам, но также по отдельным районам и городам ${ }^{12}$. Статистическая информация иногда сопровождалась краткой аналитикой демографических тенденций межпереписных периодов. Окружные управления статистики, по нашим данным, своих сборников по подведомственной территории не издавали. Основная их часть находится на хранении ведомственных архивов и в библиотеках региональных облстатов. Большой удачей можно считать обнаружение таких сборников в областных библиотеках.

Материалы Всесоюзных переписей публиковались открыто, в том числе и для последующей реализации населению. Итоги переписи 1959 г. опубликованы в 16 томах. Всесоюзная перепись 1970 г. была издана в 1972-1974 гг. в семи томах. Материалы переписи 1979 г. первоначально были опубликованы в 1984 г. в единственном сборнике. Подробные итоги были изданы в 1989-1990 гг. в десяти томах. Данные Всесоюзной переписи 1989 г. выпущены ограниченным числом кратких брошюр. Часть материалов была все-таки издана позже, правда, только по Российской Федерации.

Вышеназванные тома переписей изданы большими тиражами, их можно найти в областных библиотеках. Центральное место в них отводилось союзным республикам, информация по областям, краям и автономным республикам дана сжатой форме. Например, в семитомном издании итогов переписи 1970 г. возрастной состав округов был представлен по десятилетним когортам, уровень образования - в самом общем виде, без делений по возрастным группам, общественные группы - только по всему населению (без городского и сельского) и т. д.

Переписи дают демографическую и социальную характеристики населения в конкретный, заранее заданный момент времени. Сбор сведений о рождениях, смертях, браках и разводах осуществлялся текущим учетом населения. Согласно программе разработки демографических событий статистические органы получали разнообразную демографическую информацию, которая распределялась приблизительно по 15 формам. Разработка демографических событий по автономным округам не производилась, только по областям, краям и автономным республикам. В результате недоступными для исследователей стали важнейшие сведения о рождаемости по возрасту и очередности рождения, смертности, брачности и разводимости по возрасту, числе рождений и смертей по национальностям, числе рождений и смертей по возрасту и национальности. Частично, по округам они стали разрабатываться только в постсоветский период.

\footnotetext{
${ }^{10}$ См. напр.: Возрастной состав и состояние в браке населения РСФСР (по данным Всесоюзной переписи населения 1979 г.). М.: ЦСУ РСФСР, 1980. (ДСП).

${ }^{11}$ Национальный состав населения РСФСР (по данным Всесоюзной переписи населения на 15 января 1970 г.). М., 1975. (ДСП); Национальный состав населения РСФСР. (по данным Всесоюзной переписи населения 1979 года). М.: ЦСУ РСФСР, 1982. (ДСП).

${ }^{12}$ См. напр.: К итогам Всесоюзной переписи населения 1979 года. Иркутск, 1981. (ДСП); Численность членов семей и одиночек и группировка семей по размеру по данным Всесоюзной переписи населения 1979 г. по Иркутской области. Иркутск, 1981. (ДСП).
} 
В этой связи, невозможно рассчитать такие важные показатели как суммарный коэффициент рождаемости, ожидаемую продолжительность жизни, в том числе в этническом разрезе. В областных архивах сохранились сведения, на основе которых можно рассчитать лишь общие коэффициенты (в \%о). Прежде всего, это форма № 1-а «Общие итоги естественного движения населения». В ней содержаться сведения о числе рождений и смертей, браков и разводов по всем районам, городским поселениям области и округа. На основе такой информации в сочетании с материалами Всесоюзной переписей можно рассчитать общие коэффициенты рождаемости и смертности по округам и их административным единицам, а также механический прирост в межпереписные периоды.

Очень часто в областных архивах нет информации о естественном движении за ряд лет. Так, например, в Иркутском архиве - это 1966-1970, 1972, 1974-1976, 1978-1979 годы, в Читинском пропущен только один - 1967 год. Здесь следует сказать о том, что с такими пробелами в статистических данных сталкивается любой исследователь, работающий в русле исторической демографии. В каждом конкретном случае эта проблема решается по-разному. Одним из способов является обращение к материалам собственно окружных архивов, однако и там есть свои нюансы. Статистические управления округов не заполняли традиционных таблиц и вели учет демографических событий в произвольной форме. В итоге в окружных архивах информация о естественном движении представлена несколько бессистемно на обычных листах, где границы таблиц, их колонки очерчивались вручную.

Кроме того, в архиве Усть-Ордынского округа источники о естественном движении присутствуют, но начиная с 1982 г. В них отмечено общее количество родившихся и умерших, браков и разводов по районам, без данных о детской смертности и без деления по городским поселениям и сельской местности. В архиве Агинского округа демографическая статистика представлена с 1960 г., в основном это первичные материалы слабо пригодные для научного анализа. Первые подходящие для изучения сведения появились только с 1968 г. Они также заполнялись в свободной форме, но по сравнению с Усть-Ордынским архивом были более подробными.

Материалы текущего учета населения, также как и данные переписей, могли публиковаться в закрытых изданиях (ДСП). Насколько нам известно, окружные управления статистики своих сборников не выпускали. Если рассматривать республиканские (РСФСР) сборники, то в них сведения по автономным округам были представлены в виде общих коэффициентов смертности и рождаемости, без конкретных цифр, а выпущенные в 19671970 гг. кроме того включали в себя информацию о числе родившихся и умерших по коренным национальностям. Наиболее полно демография округов была представлена в сборниках, издаваемых областными управлениями статистики ${ }^{13}$. В них включалась почти вся информация формы № 1-а, кроме отдельных городских поселений, но к настоящему моменту они хранятся в основном в ведомственных архивах. Итак, для выявления всех данных текущего учета необходимо использовать разные методы сбора информации. В случае острой необходимости можно обратиться непосредственно к ведомственным архивам и библиотекам (официальные запросы и письма), но для этого могут потребоваться довольно значительные денежные средства.

Таким образом, анализ источников показал, что в отношении автономных округов существует солидная статистическая база, которая включает, главным образом, Всесоюзные переписи населения. Она позволяет дать объективную оценку динамике демографического и социального состава населения. Вместе с тем, окружные управления статистики не вели собственного полноценного текущего учета. Следовательно, можно дать только косвенную оценку воспроизводственным процессам, специфике демографического перехода населения округов в 1960-1980-е гг.

\footnotetext{
13 Естественное движение и миграция населения Иркутской области в 1985 году. Иркутск, 1986. (ДСП); Естественное движение населения в 1986 году. Чита, 1987. (ДСП).
} 


\section{Лumepamypa}

Дашинамжилов О.Б. Городское население Западной Сибири в 1960-1980-е годы: Историко-демографическое исследование. Новосибирск: Наука, Изд-во СО РАН, 2018. 368 с. Демографическая история Западной Сибири (конец XIX-XX в.). Новосибирск: Институт истории, 2017. $350 \mathrm{c.}$

Демографическая история России и регионов. Сб. научн. тр. Вып. I: проблемы источников. Новосибирск: Изд-во «Апельсин», 2016. 304 с.

Жиромская В.Б. Полвека под грифом «секретно»: всесоюзная перепись населения 1937 года. М.: Наука, 1996. 152 с.

Исупов B.A. Статистические источники по демографической истории России периода Великой Отечественной войны. Сыктывкар, 2011. 20 с.

\section{References}

Dashinamzhilov O.B. Gorodskoe naselenie Zapadnoy Sibiri v 1960-1980-e gody: Istorikodemograficheskoe issledovanie [Urban population of Western Siberia in 1960-1980s: HistoricalDemographic research]. Novosibirsk: Nauka, Izd-vo SO RAN, 2018. 368 p.

Demograficheskaya istoriya Zapadnoy Sibiri (konec XIX-XX v.) [Demographic history of Western Siberia (end of $19^{\text {th }}-20^{\text {th }}$ centuries]. Novosibirsk: Institut istorii, 2017. $350 \mathrm{p}$.

Demograficheskaya istoriya Rossii i regionov. Sb. nauchn. tr. Vypusk I: problemi istochnikov [Demographic History of Russia and regions. Collection of scientific works. Issue I: problems of resources]. Novosibirsk: Apelsin, 2016. 304 p.

Zhiromskaya V.B. Polveka pod grifom "sekretno": vsesoyuznaya perepis naseleniya 1937 goda [Half of a year under a "secret" label: All Union Census of population of 1937]. Moscow: Nauka, 1996. $152 \mathrm{p}$.

Isupov V.A. Statisticheskie istochniki po demograficheskoy istorii Rossii perioda Velikoy Otechestvennoy voyni [Statistical resources on demographic History of Russian period of the World War II]. Syktyvkar, 2011. 20 p.

Статья поступила в редакциию 22.07.2019 г. 